\title{
Pathways driving the endocytosis of mutant and wild-type EGFR in cancer
}

\author{
Kaia K. Hampton ${ }^{1}$ and Rolf J. Craven ${ }^{1}$ \\ 1 Department of Pharmacology and Nutritional Sciences, University of Kentucky, Lexington, KY \\ Correspondence to: Rolf J. Craven, email: rolf.craven@uky.edu \\ Keywords: signaling, endocytosis, receptor, kinase, therapeutics \\ Received: June 3, $2014 \quad$ Accepted: July 20, $2014 \quad$ Published: July 29, 2014 \\ This is an open-access article distributed under the terms of the Creative Commons Attribution License, which permits unrestricted use, \\ distribution, and reproduction in any medium, provided the original author and source are credited.
}

\section{ABSTRACT:}

EGFR (epidermal growth factor receptor) is activated through changes in expression or mutations in a number of tumors and is a driving force in cancer progression.EGFR is targeted by numerous inhibitors, including chimeric antibodies targeting the extracellular domain and small molecule kinase domain inhibitors. The kinase domain inhibitors are particularly active against mutant forms of the receptor, and subsequent mutations drive resistance to the inhibitors. Here, we review recent developments on the trafficking of wild-type and mutant EGFR, focusing on the roles of MIG6, SPRY2, ITSN, SHP2, S2R ${ }^{\text {PGRC1 }}$ and RAK.Some classes of EGFR regulators affect wild-type and mutant EGFR equally, while others are specific for either the wild-type or mutant form of the receptor.Below we summarize multiple signalingassociated pathways that are important in trafficking wild-type and mutant EGFR with the goal being stimulation of new approaches for targeting the distinct forms of the receptor.

\section{INTRODUCTION}

\section{Regulation of wild-type EGFR trafficking}

EGFR is over-expressed in a large number of tumors and is one of the best characterized oncogenic targets. EGFR binds to multiple extracellular growth factors, triggering conformational changes, dimerization of the receptor and phosphorylation of numerous residues in its cytoplasmic domain $[1,2]$. Some of the phosphorylated sites serve as docking points for downstream signaling molecules, while others are bound by negative regulatory proteins that drive endocytosis of the receptor. Specifically, $\mathrm{Cbl}$ (Casitas B-lineage lymphoma), an E3 ubiquitin ligase [3], is recruited to tyrosine 1045 phosphorylated EGFR by the adaptor protein GRB2, which promotes EGFR ubiquitylation and entrance into clathrin coated pits (Figure $1[4,5])$. There are a number of recent reviews on EGFR signaling and trafficking [6], so we will focus on several areas acting upstream on wild-type and mutant EGFR that have not been reviewed recently.

MIG6/RALT (mitogen-inducible gene/receptorassociated late transducer) inhibits EGFR [7-10] by associating with the receptor through a carboxy-terminal ERB-binding region (EBR). MIG6-EGFR binding physically obstructs EGFR asymmetric dimer formation $[8,11]$ and suppresses EGFR activity by stabilizing an inactive conformation of the receptor [12]. Many of these findings were reviewed in 2011 [13]. MIG6 decreases proliferation and migration in a variety of cell types in vitro [13]. In MIG6/Errfil knockout mice, endogenous EGFR is hyper-activated, causing hyperplasia of epidermal keratinocytes and extreme sensitivity to chemical carcinogenesis [14] that is reversed by gefitinib.

More recently, Hopkins, et al., showed that mammary gland terminal end buds in Errfl-null mice had increased luminal filling [15]. This hyper-proliferation was not due to EGFR hyper-activation but decreased ABL activity, suppressing apoptosis in this setting [15]. ABL is a cytoplasmic tyrosine kinase associated with tumor cell survival and metastasis in cancer cells but also with stressassociated apoptosis through p73 in normal tissues [1618]. MIG6 binds to ABL via its conserved ERB domain in the absence of epidermal growth factor, suggesting a 
mechanism in which MIG-6 senses EGF deprivation to induce apoptosis [15].

In addition to inhibiting EGFR catalytic activity, MIG6 increases EGFR internalization and trafficking to the lysosome [19], even for EGFR mutants that are not trafficked by CBL-mediated endocytosis [20]. Indeed, computational modeling suggests that MIG6 and CBL contribute equally to EGFR endocytosis [21], although this model is based on a limited number of cell lines. MIG6-dependent EGFR endocytosis is thought to be clathrin-dependent, involving binding between MIG6 and the SH3 domains of the intersectins ITSN1 and ITSN2 (Figure 1, [20]). Moreover, MIG6 associates with the SNARE protein syntaxin 8 (STX8, Figure 1), elevating levels of the STX8-EGFR complex, which is essential for EGFR endosomal trafficking [19]. The findings of Frosi, et al. suggests that clathrin-dependent EGFR endocytosis results in lysosomal degradation [20]. However, this model contrasts with a previous study indicating that clathrin-dependent EGFR endocytosis is associated with receptor recycling and sustained activation [22]. The latter study employed high levels of ligand, and the two studies were performed in very different cell types, HeLa [22] and mouse NR6 cells [20], implying that some aspects of EGFR endocytosis and signaling may be organism - or cell type-specific. Furthermore, there is recent biochemical evidence that MIG6 tyrosine phosphorylation weakens its ability to inhibit EGFR, even though the proteins remain associated [23]. Thus, the activation of various signaling pathways may have a profound effect on CBL function.

Although some studies suggest that MIG6 and CBL act through separate mechanisms, other findings suggest interplay between their EGFR endocytic pathways. Notably, intersectin 1 (ITSN1) forms complexes with both MIG6 and CBL, mediated by intersectin SH3 domains binding to the proline-rich carboxy-terminus of $\mathrm{CBL}$ [24] or proline-rich sequences located in the RED (RALT Endocytic Domain) of MIG6 [20], increasing repression of EGFR signaling [20] and EGFR ubiquitylation [24]. ITSN1, which has been reviewed recently [25], recruits other proteins downstream, particularly SHP2, SRC homology-2 containing phosphotyrosine phosphatase (Figure 1, [26, 27]).

SPRY2 is a CBL-binding protein [28] that can be tyrosine phosphorylated [29], driving its association with CBL and inhibiting CBL-RTK binding (Figure 1, [4]). SPRY2 is de-phosphorylated by SHP2, releasing CBL [30]. ITSN1 recruits SHP2 to SPRY2, disrupting the inhibitory effect of SPRY2 on CBL, promoting EGFR ubiquitylation and endocytosis (Figure 1, [26]). SPRY2 has been extensively reviewed elsewhere [31]. However, the role of the MIG6-ITSN complex in regulating CBLSPRY complex formation is presently unknown. Thus, the interactions between EGFR, CBL, ITSN and MIG6 may be overlapping, perhaps to fine tune the temporal signaling through the receptor and to provide redundancy in the system.

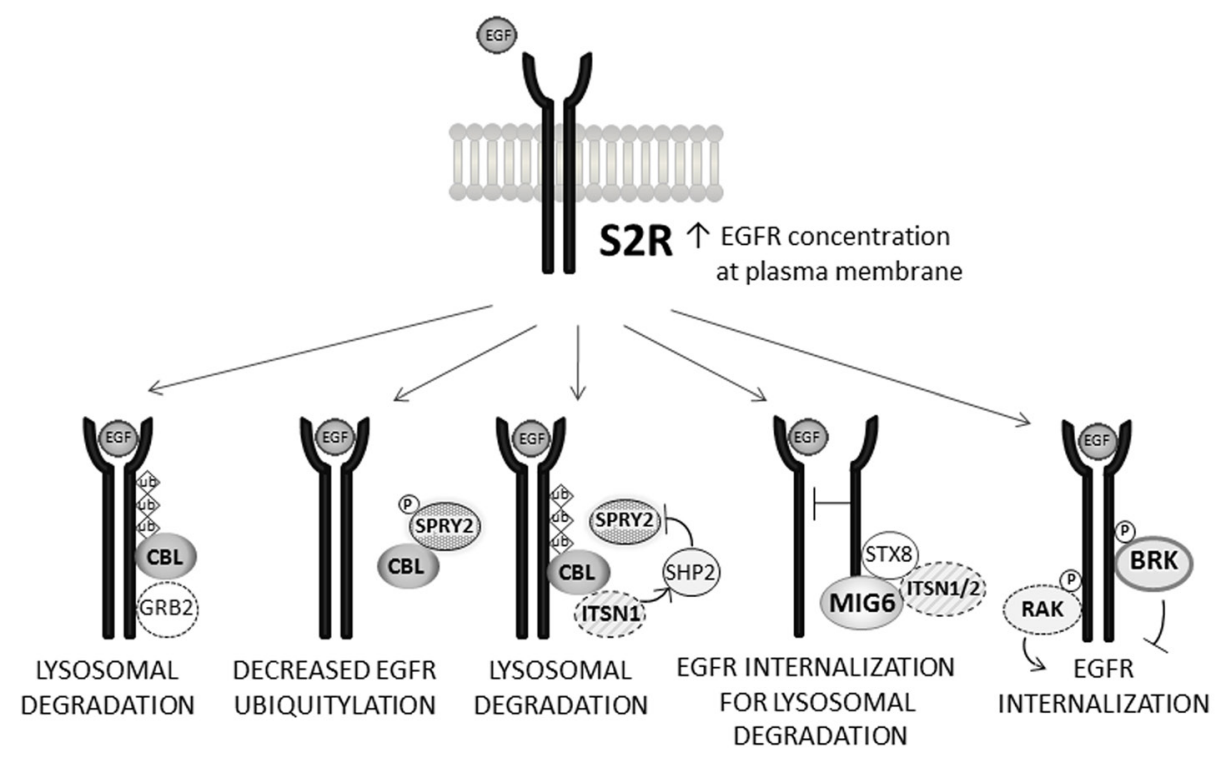

Figure 1: Selected pathways regulating EGFR endocytosis and degradation. In the top panel, EGFR levels at the plasma membrane are increased by S2R ${ }^{\text {PGRMC1}}$. The diagrams, from left to right, below, show different binding partners for EGFR. GRB2 recruits CBL to EGFR resulting in lysosomal degradation. SPRY2 phosphorylation drives its association with CBL, inhibiting CBL binding to EGFR. ITSN1 can recruit SHP2 to dephosphorylate SPRY2, releasing CBL to bind EGFR. MIG6 physically obstructs EGFR dimerization and binds to STX8 and ITSN1/2 to promote lysosomal degradation of EGFR. BRK phosphorylates EGFR to inhibit EGFR internalization, while RAK/FRK has the opposite activity. 
Sigma-2 receptor associates with EGFR, increases plasma membrane EGFR levels and promotes invasion

PGRMC1 (progesterone receptor membrane component 1 ) is a cytochrome $\mathrm{b}_{5}$-related protein that binds heme and is implicated in cellular trafficking [32]. There are compelling data that PGRMC1 is identical to the sigma-2 receptor (S2R). A highly selective S2R probe cross-linked directly to PGRMC1; S2R ligand binding decreased with PGRMC1-knockdown and increased with PGRMC1 overexpression; the apoptotic activity of an S2R ligand decreased with PGRMC1 knockdown; the PGRMC1 ligand AG-205 displaced S2R ligand binding [33, 34]. Notably, PGRMC1 was proposed to be a sigma receptor more than a decade earlier based on the ability of some sigma ligands to displace microsomal progesterone binding [35]. It is still formally possible that PGRMC1 is not itself the S2R but is part of a complex that is tightly associated with S2R, and numerous experiments are under way to further dissect this possibility. $\mathrm{S} 2 \mathrm{R}^{\text {PGRMC1 }}$ also plays a key role in membrane-associated progesterone signaling [36-38], but $\mathrm{S}_{2} \mathrm{R}^{\mathrm{PGRMC1}}$ is not homologous to known steroid receptors and direct binding of progesterone to recombinant PGRMC1 has not been demonstrated. However, progesterone binding was detected to partially purified PGRMC1 [38], and RNAi inhibition of PGRMC1 decreased progesterone binding activity [38] suggesting that $\mathrm{S} 2 \mathrm{R}^{\mathrm{PGRMCl}}$ may influence progesterone signaling through a binding partner. Indeed, Thomas, et al. demonstrated that PGRMC1 forms a complex with $\mathrm{mPR} \alpha$ and recruits the receptor to the plasma membrane [39]. Together, these proteins may be part of a larger membrane progesterone receptor complex.

In many peripheral tissues and in tumors, numerous groups have localized $\mathrm{S} 2 \mathrm{R}^{\mathrm{PGRMCl}}$ to the endoplasmic reticulum, endosomes, intracellular puncta and microsomal fractions [40-42]. Interestingly, $\mathrm{S} 2 \mathrm{R}^{\text {PGRMC1 }}$ localizes to a significant extent to the plasma membrane [43-45] and nucleus [46] in neuronal cells, and its interactions with receptors may occur at the plasma membrane in those tissues. Indeed, it is intriguing to speculate that $\mathrm{S} 2 \mathrm{R}^{\mathrm{PGRMCl}}$ might bind to a membrane progesterone receptor in neuronal tissues, where $\mathrm{S} 2 \mathrm{R}^{\mathrm{PGRMC1}}$ is co-expressed with membrane progesterone receptors [44], although this model is currently untested.

A number of groups have found that $\mathrm{S} 2 \mathrm{R}^{\mathrm{PGRMC1}}$ plays a profound role in regulating cellular signaling, particularly the Akt and ERK pathways [33, 40, 47, 48], and in searching for the mechanism underlying this effect, we found that $\mathrm{S} 2 \mathrm{R}^{\text {PGRMC1 }}$ associates with EGFR and co-localizes with EGFR within endosomes [40]. Furthermore, S2R ${ }^{\text {PGRMC1 }}$ inhibition decreased plasma membrane levels of EGFR (Figure 1), and EGFR was de-stabilized by S2R ${ }^{\text {PGRMC1 }}$ inhibition in some - but not all - cell types [40]. Thus, we propose a model that $\mathrm{S} 2 \mathrm{R}^{\mathrm{PGRMCl}}$ contributes to the trafficking of EGFR to the plasma membrane. An alternate model is that $\mathrm{S} 2 \mathrm{R}^{\mathrm{PGRMC1}}$ inhibits the endocytosis of EGFR, but $\mathrm{S}^{\mathrm{R}} \mathrm{R}^{\mathrm{PGRC1}}$ was not detected at the plasma membrane in lung cancer cells [40], suggesting that any inhibition would be indirect.

Because S2R ${ }^{\text {PGRMC1 }}$ associates with EGFR, we searched for downstream events regulated by this interaction and found that $\mathrm{S} 2 \mathrm{R}^{\mathrm{PGRMCl}}$ has a profound impact on protease activation in lung cancer cells [49]. Specifically, the $S 2 \mathrm{R}^{\mathrm{PGRMCl}}$-EGFR complex increases the Lys310 acetylation and Ser535 phosphorylation of the NF- $\mathrm{KB}$ transcription factor, which in turn drives the expression of NGAL/LCN2 [49], a binding protein for matrix metalloproteinases such as MMP9 [50]. Indeed, MMP9 activity was largely dependent on $\mathrm{S} 2 \mathrm{R}^{\mathrm{PGRMC1}}$ expression in lung cancer cells. These activities required EGFR and were elevated by exogenous EGFR expression [49]. We note that other proteases, including MMP-2 and cathepsin $\mathrm{D}$, were also activated in an $\mathrm{S} 2 \mathrm{R}^{\text {PGRMCl}}$-dependent manner [49], and cathepsin D plays a key role in tumor invasion and metastasis [51].

$\mathrm{S} 2 \mathrm{R}^{\text {PGRMC1 }}$ is appealing as a cancer target because recent events suggest that it can be efficiently inhibited both by "PGRMC1" ligands, such as AG-205 [33, 52], and by a number of small molecule "sigma- 2 receptor" ligands, including siramesine, PB28, SV119, CB-64D, SM-21 and others [53-58]. Some of these ligands have been extensively tested in vitro, in vivo and in clinical trials and had relatively minimal side effects. However, it is unclear whether any of these ligands alter EGFR trafficking. The interactions

Table 1: EGFR-L858R and EGFR- $\Delta$ 746-750 mutants differ from wild-type EGFR in regulation and trafficking. Question marks indicate unknown, and a negative sign implies no effect.

\begin{tabular}{|l|l|l|l|}
\hline & Wild-type & L858R & $\Delta 746-750$ \\
\hline Endocytosis by MIG6 & +++ & +++ & +++ \\
\hline Endocytosis by RAK & + & $?$ & +++ \\
\hline Prevents endocytosis by SPRY2 & +++ & $?$ & +++ \\
\hline S2R association & +++ & $?$ & $+/-$ \\
\hline Sensitivity to S2R inhibitor & +++ & $?$ & - \\
\hline MIG6 Expression & + & ++ & $?$ \\
\hline MIG6 tyrosine phosphorylation & + & ++ & ++ \\
\hline Impaired nuclear localization & - & + & $?$ \\
\hline CBL association & ++ & ++ & - \\
\hline
\end{tabular}


between these ligands and progesterone will likely reveal new elements of the $\mathrm{S} 2 \mathrm{R}^{\mathrm{PGRMC1}}$ mechanism.

\section{RAK/FRK increases EGFR trafficking}

Our efforts in studying EGFR led to a second heretofore unknown pathway regulating EGFR trafficking. SRC family intracellular tyrosine kinases associate with growth factor receptors, including EGFR, and are important in mitogenic signaling through these receptors [59]. Indeed, SRC was the proto-typical oncogene, being mutated in transforming avian viruses. There are eight SRC-related tyrosine kinases with a common SH2 (SRC homology)-SH3 domain structure and a myristoylation site at the amino terminus [60]. The BRK/RAK/SRC42A/ SRM kinases form a subgroup of proteins called the BRK family, that are related to SRC structurally but differ in the amino terminal sequences and multiple other sites [61]. In addition, the $\mathrm{BRK} / \mathrm{RAK} / \mathrm{SRC} 42 \mathrm{~A} / \mathrm{SRM}$ proteins have widely divergent roles in cell proliferation.

While the majority of SRC-related kinases have a positive role on cell proliferation and survival, the RAK/ FRK (FYN-related kinase [62, 63]) inhibits growth when expressed in a number of cancer cell types [64, 65]. RAK/FRK phosphorylates and binds to the PTEN tumor suppressor, stabilizing PTEN and promoting growth arrest, both in vitro and in vivo [66]. In addition, RAK/FRK associates with the RB (retinoblastoma) tumor suppressor [64] and phosphorylates a negative regulatory site on SRC [62]. Thus, there are multiple potential mechanisms through which RAK/FRK can inhibit cell growth.

We found that RAK phosphorylated tyrosine 1173 of EGFR and co-precipitated with EGFR [67]. The RAK-EGFR interaction required both the $\mathrm{SH} 2$ and $\mathrm{SH} 3$ domains of RAK and increased after EGF stimulation. As a result, RAK decreased the levels of EGFR at the plasma membrane (Figure 1, [67]), although it is unclear whether this was due to increased EGFR endocytosis, decreased EGFR transport to the plasma membrane, or some other factor.

Interestingly, BRK/PTK6 (breast tumor kinase/ protein tyrosine kinase 6) also binds to EGFR and phosphorylates the receptor [68]. In addition, BRK phosphorylates CBL and promotes its degradation [69], potentially decreasing EGFR endocytosis (Figure 1). BRK/PTK6 drives breast tumor formation in vivo in mouse models $[70,71]$ and xenografts $[71]$. BRK is also a key effector of the MET receptor tyrosine kinase [71-73], and its stability is elevated by HER2 [74, 75].

Thus, two closely related RAK-BRK family members associate with EGFR, although their functions in the complex are opposite. The third family member, SRC42A, inhibits tyrosine kinase activity in Drosophila [76] in addition to playing a key role in development. SRM (SRC related kinase lacking C-terminal regulatory tyrosine and $\mathrm{N}$-terminal myristylation sites) is induced in tumors and phosphorylates docking protein 11 [77] but does not perform an essential role in development [78], and any association with EGFR is unknown. It is intriguing to speculate that the EGFR-BRK and EGFR-RAK complexes (and possibly SRM or SRC42A complexes in Drosophila) may form in very different environments and with different dynamics during signaling.

\section{EGFR mutants drive tumor growth and have altered intracellular trafficking}

Mutant forms of EGFR are associated with cancer development, including lung cancer in non-smokers, and with elevated sensitivity to EGFR inhibitors [79-83], such as erlotinib and gefitinib. It has become increasingly clear that distinct EGFR mutants have different patterns of regulation and trafficking (Table 1). For example, Furukawa, et al. reported that EGFR- $\Delta 746-750$ has sustained activation of downstream effectors and is not phosphorylated on Y1045, the CBL binding site, resulting in impaired endocytosis [84]. In the EGFR-L858R mutant, Y1045 is phosphorylated $(81,82,83)$. However, in human cancer cells, EGFR-L858R is down-regulated [85, 86], but

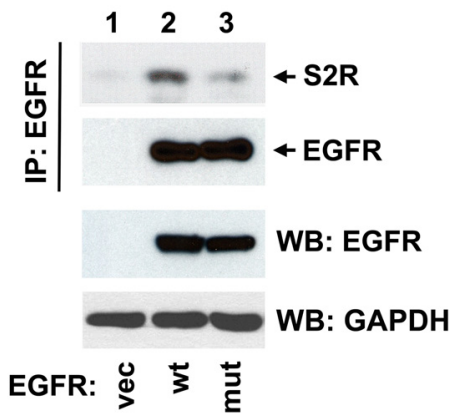

Figure 2: $\mathbf{S} 2 \mathrm{R}^{\mathrm{PGRMC1}}$ preferentially associates with wild-type EGFR. MDA-MB-435 human breast cancer cells, which do not express EGFR (lower panel, lane 1 ), were transfected with a control plasmid (lane 1), the plasmid pcDNA3.1-EGFR (lane 2, a gift from Drs. Penni Black, University of Kentucky, and William Pao, Vanderbilt University) or the plasmid pBabe-EGFR- $\Delta 746-749 / A 750 P$ Addgene, Cambridge, MA). In the top two panels, lysates were immuno-precipitated using previously described conditions [40] with the anti-EGFR antibody IMC-C225 (Erbitux, ImClone Systems, Branchburg, NJ). Precipitates were then analyzed by western blot with (top panel) the anti-S2R ${ }^{\text {PGRMC1 }}$ antibody PGR-UK1 [33] or (middle panel) an anti-EGFR polyclonal antibody (1005, Santa Cruz Biotechnology). Because of the very different molecular weights of the proteins, the blot was cut in half before probing. The bottom panels show the same unprecipitated cell lysates that were used for the precipitation reactions analyzed by western blot using EGFR and GAPDH polyclonal antibodies, the latter as a control for protein loading. The result shown is representative of three independent experiments. We have previously shown that the EGFR- $\Delta 746-749 / \mathrm{A} 750 \mathrm{P}$ mutant is highly tyrosine phosphorylated in this system compared to wild-type EGFR [67]. 
their assessment of ubiquitylation and CBL binding were markedly different $[85,86]$. In contrast, Furukawa, et al., found normal EGFR-L858R-CBL binding with unaffected downstream signaling [84]. However, the latter studies were in mouse fibroblasts and simian COS-7 cells and may not reflect the signaling environment of cancer cells. The EGFR-L858R mutant has impaired nuclear EGFR localization resulting in decreased DNA repair activity [87]. Interestingly, the EGFRvIII mutant is also trafficked atypically, with the majority of the receptor being recycled to the plasma membrane rather than being degraded, even though the EGFRvIII mutation is on the extracellular surface of the protein [88].

MIG6 expression is elevated in cells expressing EGFR-L858R [89], and MIG6 is required for the endocytosis of wild-type and mutant $\operatorname{EGFR~[89,90].~}$ However, MIG6 tyrosine phosphorylation is elevated in cells expressing EGFR-L858R and EGFR- $\Delta 746-750$ [91], suggesting a weaker ability to inhibit the receptor (Table 1). SPRY2 prevents endocytosis of both wildtype and $\Delta 746-749 /$ A750 mutant EGFR [90]. Thus, in a limited number of cell lines, MIG6 and SPRY2 do not discriminate between wild-type and mutant EGFR in their endocytic functions [90]. However, a recent study suggests that, although MIG6 is more efficient against the wildtype EGFR, it has an increased role in the endocytosis of EGFR $\Delta 746$-A750 compared to wild-type EGFR, because CBL is less active against the mutant [21]. The EGFRvIII mutant does not undergo ligand-induced endocytosis due to low levels of phosphorylation [92], and MIG6 is inactive against it [19].

In contrast to MIG6 and SPRY, S2R ${ }^{\text {PGRMC1 }}$ does not act equally on wild-type and mutant EGFR. An S2R ${ }^{\text {PGRC1 }}$ inhibitor was active against cells expressing wild-type EGFR, but had no activity against lung cancer cells expressing EGFR mutants [40]. However, the cell lines had different genetic backgrounds, and factors other than EGFR could have affected S2R ${ }^{\text {PGRMC1 }}$ inhibitor sensitivity. For that reason, we expressed wild-type EGFR and the EGFR- $4747-749 / A 750$ P mutant in MDA-MB-435 cells, which do not express EGFR, and found that S2R ${ }^{\text {PGRMC1 }}$ coprecipitated with wild-type EGFR-2.4-fold more than the mutant (Fig 2). The mechanism underlying this specificity is unclear. However, S2 $\mathrm{R}^{\text {PGRMC1 }}$ is enriched in endosomes in lung cancer cells [40], and the decreased endocytosis of mutant EGFR may limit the access of the two receptors to each other. Because S2R ${ }^{\text {PGRMCl }}$ binds mutant EGFR poorly (and inhibitors are inactive against cells expressing it), we do not expect that S2R functions through a SPRY pathway for EGFR regulation.

In stark contrast to $\mathrm{S} 2 \mathrm{R}^{\mathrm{PGRMC} 1}$, we found that $\mathrm{RAK}$ FRK bound preferentially to the EGFR $\Delta 746-749 /$ A750P mutant compared to the wild-type protein [67]. This may be due to the increased activity of the mutant EGFR, because RAK binding to wild-type EGFR increased after ligand stimulation [67]. The results suggest that RAK may have elevated tumor suppressive activity in tissues expressing mutant EGFR. It is intriguing to speculate that tumors expressing mutant EGFR may have decreased RAK expression, but this concept has not been tested. Because RAK and MIG6 are both active against EGFR mutants, it is intriguing to speculate that they may be mechanistically related. However, this remains to be tested.

\section{PERSPECTIVES: CURRENT AND FUTURE WORK}

Mutant forms of EGFR are associated with some types of cancer and have differential trafficking compared to the wild-type receptor. Furthermore, specific trafficking proteins are distinct in their regulation of wild-type and mutant EGFR. In spite of the dramatic advances in the field, there are numerous questions remaining about MIG6, such as the conditions under which its tyrosine phosphorylation changes and the key players directing these alterations. In addition, new targets for MIG6 play key roles in proliferation and apoptosis. In normal tissues lacking MIG6, breast cells proliferated due to loss of ABL [15], but it is unclear how the MIG6-ABL interaction changes in different non-malignant cell types and during cancer progression. In normal tissues, ABL is thought to be pro-apoptotic, while in cancer cells, ABL drives proliferation, survival and metastasis. But it is unknown whether ABL no longer binds MIG6 in cancer cells or whether binding changes in the presence of apoptotic stimuli.

The relatively poor binding of $\mathrm{S} 2 \mathrm{R}^{\mathrm{PGRMC1}}$ to the EGFR- $4746-749 / A 750$ P mutant (Figure 2) may offer important clues to its interaction with EGFR. If the mutant is sustained at the plasma membrane, it is likely that $\mathrm{S} 2 \mathrm{R}^{\mathrm{PGRMC1}}$ is prevented from binding to mutant EGFR because EGFR is not internalized, consistent with the endosomal localization of $\mathrm{S} 2 \mathrm{R}^{\mathrm{PGRMC} 1}$ in lung cancer cells [40]. For wild-type EGFR, EGF stimulation did not affect EGFR-S2R ${ }^{\text {PGRMC1 }}$ binding [40], suggesting that the activated state of EGFR- $\Delta 746-749 / \mathrm{A} 750 \mathrm{P}$ is not responsible for the change in binding to $S 2 R^{\text {PGRMC1 }}$. Future work will include a broader analysis of S2 $\mathrm{R}^{\text {PGRMC1 }}$ binding to additional EGFR mutants, particularly EGFR-L858R.

The RAK/FRK tyrosine kinase decreases the plasma membrane pools of EGFR, and it is intriguing to speculate that RAK/FRK might influence the phosphorylation of EGFR trafficking proteins, including SPRY2, MIG6 and ITSN. We predict that RAK/FRK would increase MIG6 activity, possibly by decreasing MIG6 tyrosine phosphorylation. Conversely, we speculate that RAK/ FRK might decrease the tyrosine phosphorylation of SPRY2, because SPRY2 phosphorylation is associated with decreased EGFR ubiquitylation (Figure 1). Current research is focusing on the role of RAK/FRK-PTEN binding in regulating EGFR. 


\section{CONCLUSIONS}

EGFR levels at the plasma membrane are balanced by competing positive and negative mediators. The impact of these pathways changes for the mutant forms of the receptor, and some of the regulatory proteins have altered expression in cancer. While kinase inhibitors are active against tumors expressing mutant EGFR, their activity is limited against those expressing wild-type EGFR, and some activities of EGFR may be kinase-independent. S2R ${ }^{\mathrm{PGRMCl}}$ inhibitors are attractive in this setting because they inhibit EGFR-dependent cancer cell proliferation and are most active against the wild-type form of the protein [40].

\section{ACKNOWLEDGEMENTS}

This research was funded in part by a grant from the Bonnie J Addario Lung Cancer Research Foundation.

\section{REFERENCES}

1. Lemmon MA and Schlessinger J. Cell signaling by receptor tyrosine kinases. Cell. 2010; 141:1117-1134.

2. Hynes NE and Lane HA. ERBB receptors and cancer:the complexity of targeted inhibitors. Nat Rev Cancer. 2005; 5:341-354.

3. Langdon WY, Hartley JW, Klinken SP, Ruscetti SK and Morse HC, 3rd. v-cbl, an oncogene from a dual-recombinant murine retrovirus that induces early B-lineage lymphomas. Proc Natl Acad Sci U S A. 1989; 86:1168-1172.

4. Schmidt $\mathrm{MH}$ and Dikic I. The Cbl interactome and its functions. Nat Rev Mol Cell Biol. 2005; 6:907-918.

5. Levkowitz G, Waterman H, Zamir E, Kam Z, Oved S, Langdon WY, Beguinot L, Geiger B and Yarden Y. c-Cbl/ Sli-1 regulates endocytic sorting and ubiquitination of the epidermal growth factor receptor. Genes Dev. 1998; 12:3663-3674.

6. Tomas A, Futter CE and Eden ER. EGF receptor trafficking:consequences for signaling and cancer. Trends Cell Biol. 2014; 24:26-34.

7. Anastasi S, Sala G, Huiping C, Caprini E, Russo G, Iacovelli S, Lucini F, Ingvarsson S and Segatto O. Loss of RALT/MIG-6 expression in ERBB2-amplified breast carcinomas enhances ErbB-2 oncogenic potency and favors resistance to Herceptin. Oncogene. 2005; 24: 4540-4548.

8. $\mathrm{Xu} \mathrm{D,} \mathrm{Makkinje} \mathrm{A} \mathrm{and} \mathrm{Kyriakis} \mathrm{JM.} \mathrm{Gene} 33$ is an endogenous inhibitor of epidermal growth factor (EGF) receptor signaling and mediates dexamethasone-induced suppression of EGF function. J Biol Chem. 2005; 280: 2924-2933.

9. Hackel PO, Gishizky M and Ullrich A. Mig-6 is a negative regulator of the epidermal growth factor receptor signal. Biol Chem. 2001; 382: 1649-1662.
10. Anastasi S, Fiorentino L, Fiorini M, Fraioli R, Sala G, Castellani L, Alema S, Alimandi M and Segatto O. Feedback inhibition by RALT controls signal output by the ErbB network. Oncogene. 2003; 22: 4221-4234.

11. Anastasi S, Baietti MF, Frosi Y, Alema S and Segatto O. The evolutionarily conserved EBR module of RALT/ MIG6 mediates suppression of the EGFR catalytic activity. Oncogene. 2007; 26: 7833-7846.

12. Zhang X, Pickin KA, Bose R, Jura N, Cole PA and Kuriyan J. Inhibition of the EGF receptor by binding of MIG6 to an activating kinase domain interface. Nature. 2007; 450(7170): 741-744.

13. Segatto O, Anastasi S and Alema S. Regulation of epidermal growth factor receptor signalling by inducible feedback inhibitors. J Cell Sci. 2011; 124(Pt 11): 1785-1793.

14. Ferby I, Reschke M, Kudlacek O, Knyazev P, Pante G, Amann K, Sommergruber W, Kraut N, Ullrich A, Fassler R and Klein R. Mig6 is a negative regulator of EGF receptormediated skin morphogenesis and tumor formation. Nature Med. 2006; 12: 568-573.

15. Hopkins S, Linderoth E, Hantschel O, Suarez-Henriques P, Pilia G, Kendrick H, Smalley MJ, Superti-Furga G and Ferby I. Mig6 is a sensor of EGF receptor inactivation that directly activates c-Abl to induce apoptosis during epithelial homeostasis. Dev Cell. 2012; 23: 547-559.

16. Tsai KK and Yuan ZM. c-Abl stabilizes p73 by a phosphorylation-augmented interaction. Cancer Res. 2003; 63: 3418-3424.

17. Wang JY. Nucleo-cytoplasmic communication in apoptotic response to genotoxic and inflammatory stress. Cell Res. 2005; 15: 43-48.

18. Ganguly SS and Plattner R. Activation of abl family kinases in solid tumors. Genes \& cancer. 2012; 3(5-6): 414-425.

19. Ying $H$, Zheng $H$, Scott $K$, Wiedemeyer R, Yan H, Lim C, Huang J, Dhakal S, Ivanova E, Xiao Y, Zhang H, Hu J, Stommel JM, Lee MA, Chen AJ, Paik JH, et al. Mig-6 controls EGFR trafficking and suppresses gliomagenesis. Proc Natl Acad Sci U S A. 2010; 107: 6912-6917.

20. Frosi Y, Anastasi S, Ballaro C, Varsano G, Castellani L, Maspero E, Polo S, Alema S and Segatto O. A two-tiered mechanism of EGFR inhibition by RALT/MIG6 via kinase suppression and receptor degradation. J Cell Biol. 2010; 189: 557-571.

21. Walsh AM and Lazzara MJ. Differential parsing of EGFR endocytic flux among parallel internalization pathways in lung cancer cells with EGFR-activating mutations. Integr Biol (Camb). 2014; 6: 312-323.

22. Sigismund S, Argenzio E, Tosoni D, Cavallaro E, Polo $\mathrm{S}$ and Di Fiore PP. Clathrin-mediated internalization is essential for sustained EGFR signaling but dispensable for degradation. Dev Cell. 2008; 15: 209-219.

23. Wang Z, Raines LL, Hooy RM, Roberson H, Leahy DJ and Cole PA. Tyrosine phosphorylation of mig6 reduces 
its inhibition of the epidermal growth factor receptor. ACS Chem Biol. 2013; 8: 2372-2376.

24. Martin NP, Mohney RP, Dunn S, Das M, Scappini E and O'Bryan JP. Intersectin regulates epidermal growth factor receptor endocytosis, ubiquitylation, and signaling. Mol Pharmacol. 2006; 70: 1643-1653.

25. Hunter MP, Russo A and O'Bryan JP. Emerging Roles for Intersectin (ITSN) in Regulating Signaling and Disease Pathways. Int J Mol Sci. 2013; 14: 7829-7852.

26. Okur MN, Russo A and O'Bryan JP. Receptor tyrosine kinase ubiquitylation involves the dynamic regulation of Cbl-Spry2 by intersectin 1 and the Shp2 tyrosine phosphatase. Mol Cell Biol. 2014; 34: 271-279.

27. Pawson T and Gish GD. SH2 and SH3 domains:from structure to function. Cell. 1992; 71: 359-362.

28. Wong ES, Lim J, Low BC, Chen Q and Guy GR. Evidence for direct interaction between Sprouty and Cbl. J Biol Chem. 2001; 276: 5866-5875.

29. Hanafusa H, Torii S, Yasunaga T and Nishida E. Sprouty 1 and Sprouty2 provide a control mechanism for the Ras/ MAPK signalling pathway. Nat Cell Biol. 2002; 4: 850-858.

30. Hanafusa H, Torii S, Yasunaga T, Matsumoto K and Nishida E. Shp2, an SH2-containing protein-tyrosine phosphatase, positively regulates receptor tyrosine kinase signaling by dephosphorylating and inactivating the inhibitor Sprouty. J Biol Chem. 2004; 279: 22992-22995.

31. Guy GR, Jackson RA, Yusoff P and Chow SY. Sprouty proteins:modified modulators, matchmakers or missing links? J Endocrinol. 2009; 203: 191-202.

32. Rohe HJ, Ahmed IS, Twist KE and Craven RJ. PGRMC1 (progesterone receptor membrane component 1):a targetable protein with multiple functions in steroid signaling, P450 activation and drug binding. Pharmacol Ther. 2009; 121: 14-19.

33. Ahmed IS, Rohe HJ, Twist KE, Mattingly MN and Craven RJ. Progesterone receptor membrane component 1 (Pgrmc1):a heme-1 domain protein that promotes tumorigenesis and is inhibited by a small molecule. J Pharmacol Exp Ther. 2010; 333: 564-573.

34. Xu J, Zeng C, Chu W, Pan F, Rothfuss JM, Zhang F, Tu Z, Zhou D, Zeng D, Vangveravong S, Johnston F, Spitzer D, Chang KC, Hotchkiss RS, Hawkins WG, Wheeler KT, et al. Identification of the PGRMC1 protein complex as the putative sigma-2 receptor binding site. Nat Commun. 2011; 2: 380.

35. Meyer C, Schmieding K, Falkenstein E and Wehling M. Are high-affinity progesterone binding site(s) from porcine liver microsomes members of the sigma receptor family? Eur $\mathrm{J}$ Pharmacol. 1998; 347(2-3): 293-299.

36. Liu L, Wang J, Zhao L, Nilsen J, McClure K, Wong $\mathrm{K}$ and Brinton RD. Progesterone increases rat neural progenitor cell cycle gene expression and proliferation via extracellularly regulated kinase and progesterone receptor membrane components 1 and 2. Endocrinology. 2009; 150:
3186-3196.

37. Peluso JJ, Pappalardo A, Losel $\mathrm{R}$ and Wehling $\mathrm{M}$. Progesterone membrane receptor component 1 expression in the immature rat ovary and its role in mediating progesterone's antiapoptotic action. Endocrinology. 2006; 147: 3133-3140.

38. Peluso JJ, Romak J and Liu X. Progesterone receptor membrane component-1 (PGRMC1) is the mediator of progesterone's antiapoptotic action in spontaneously immortalized granulosa cells as revealed by PGRMC1 small interfering ribonucleic acid treatment and functional analysis of PGRMC1 mutations. Endocrinology. 2008; 149: 534-543.

39. Thomas P, Pang Y and Dong J. Enhancement of cell surface expression and receptor functions of membrane progestin receptor alpha (mPRalpha) by progesterone receptor membrane component 1 (PGRMC1):evidence for a role of PGRMC1 as an adaptor protein for steroid receptors. Endocrinology. 2014; 155: 1107-1119.

40. Ahmed IS, Rohe HJ, Twist KE and Craven RJ. Pgrmc1 (progesterone receptor membrane component 1) associates with epidermal growth factor receptor and regulates erlotinib sensitivity. J Biol Chem. 2010; 285: 24775-24782.

41. Nolte I, Jeckel D, Wieland FT and Sohn K. Localization and topology of ratp28, a member of a novel family of putative steroid-binding proteins. Biochim Biophys Acta. 2000; 1543: 123-130.

42. Meyer C, Schmid R, Scriba PC and Wehling M. Purification and partial sequencing of high-affinity progesterone-binding site(s) from porcine liver membranes. Eur J Biochem. 1996; 239: 726-731.

43. Krebs CJ, Jarvis ED, Chan J, Lydon JP, Ogawa S and Pfaff DW. A membrane-associated progesterone-binding protein, $25-\mathrm{Dx}$, is regulated by progesterone in brain regions involved in female reproductive behaviors. Proc Natl Acad Sci U S A. 2000; 97: 12816-12821.

44. Su C, Cunningham RL, Rybalchenko N and Singh M. Progesterone increases the release of brain-derived neurotrophic factor from glia via progesterone receptor membrane component 1 (Pgrmc1)-dependent ERK5 signaling. Endocrinology. 2012; 153: 4389-4400.

45. Labombarda F, Gonzalez SL, Deniselle MC, Vinson GP, Schumacher M, De Nicola AF and Guennoun R. Effects of injury and progesterone treatment on progesterone receptor and progesterone binding protein 25-Dx expression in the rat spinal cord. J Neurochem. 2003; 87: 902-913.

46. Bali N, Arimoto JM, Iwata N, Lin SW, Zhao L, Brinton RD, Morgan TE and Finch CE. Differential responses of progesterone receptor membrane component-1 (Pgrmc1) and the classical progesterone receptor (Pgr) to 17betaestradiol and progesterone in hippocampal subregions that support synaptic remodeling and neurogenesis. Endocrinology. 2012; 153: 759-769.

47. Neubauer H, Clare SE, Wozny W, Schwall GP, Poznanovic 
S, Stegmann W, Vogel U, Sotlar K, Wallwiener D, Kurek R, Fehm T and Cahill MA. Breast cancer proteomics reveals correlation between estrogen receptor status and differential phosphorylation of PGRMC1. Breast Cancer Res. 2008; 10: R85.

48. Hand RA and Craven RJ. Hpr6.6 protein mediates cell death from oxidative damage in MCF-7 human breast cancer cells. J Cell Biochem. 2003; 90: 534-547.

49. Mir SU, Jin L and Craven RJ. Neutrophil gelatinaseassociated lipocalin (NGAL) expression dependent on the tumor-associated sigma-2 receptor S2RPgrmc1. J Biol Chem. 2012.

50. Bolignano D, Donato V, Lacquaniti A, Fazio MR, Bono C, Coppolino G and Buemi M. Neutrophil gelatinaseassociated lipocalin (NGAL) in human neoplasias:a new protein enters the scene. Cancer Lett. 2010; 288: 10-16.

51. Joyce JA, Baruch A, Chehade K, Meyer-Morse N, Giraudo E, Tsai FY, Greenbaum DC, Hager JH, Bogyo M and Hanahan D. Cathepsin cysteine proteases are effectors of invasive growth and angiogenesis during multistage tumorigenesis. Cancer Cell. 2004; 5: 443-453.

52. Yoshitani N, Satou K, Saito K, Suzuki S, Hatanaka H, Seki M, Shinozaki K, Hirota H and Yokoyama S. A structurebased strategy for discovery of small ligands binding to functionally unknown proteins:combination of in silico screening and surface plasmon resonance measurements. Proteomics. 2005; 5: 1472-1480.

53. Ostenfeld MS, Fehrenbacher N, Hoyer-Hansen M, Thomsen C, Farkas T and Jaattela M. Effective tumor cell death by sigma-2 receptor ligand siramesine involves lysosomal leakage and oxidative stress. Cancer Res. 2005; 65: 89758983.

54. Ghelardini C, Galeotti N, Gualtieri F, Bellucci C, Manetti D, Giotti A, Malmberg-Aiello P, Galli A and Bartolini A. Antinociceptive profile of 3-alpha-tropanyl 2-(4-Clphenoxy)butyrate (SM-21) [corrected]:a novel analgesic with a presynaptic cholinergic mechanism of action. J Pharmacol Exp Ther. 1997; 282: 430-439.

55. Berardi F, Ferorelli S, Abate C, Colabufo NA, Contino M, Perrone R and Tortorella V. 4-(tetralin1-yl) - and 4-(naphthalen-1-yl)alkyl derivatives of 1-cyclohexylpiperazine as sigma receptor ligands with agonist sigma2 activity. J Med Chem. 2004; 47: 2308-2317.

56. Zeng C, Vangveravong S, Xu J, Chang KC, Hotchkiss RS, Wheeler KT, Shen D, Zhuang ZP, Kung HF and Mach RH. Subcellular localization of sigma-2 receptors in breast cancer cells using two-photon and confocal microscopy. Cancer Res. 2007; 67: 6708-6716.

57. Crawford KW and Bowen WD. Sigma-2 receptor agonists activate a novel apoptotic pathway and potentiate antineoplastic drugs in breast tumor cell lines. Cancer Res. 2002; 62: 313-322.

58. Kashiwagi H, McDunn JE, Simon PO, Jr., Goedegebuure PS, Xu J, Jones L, Chang K, Johnston F, Trinkaus K,
Hotchkiss RS, Mach RH and Hawkins WG. Selective sigma-2 ligands preferentially bind to pancreatic adenocarcinomas:applications in diagnostic imaging and therapy. Mol Cancer. 2007; 6: 48.

59. Bromann PA, Korkaya $\mathrm{H}$ and Courtneidge SA. The interplay between Src family kinases and receptor tyrosine kinases. Oncogene. 2004; 23: 7957-7968.

60. Boggon TJ and Eck MJ. Structure and regulation of Src family kinases. Oncogene. 2004; 23: 7918-7927.

61. Serfas MS and Tyner AL. Brk, Srm, Frk, and Src42A form a distinct family of intracellular Src-like tyrosine kinases. Oncology Res. 2003; 13(6-10): 409-419.

62. Cance WG, Craven RJ, Bergman M, Xu L, Alitalo K and Liu ET. Rak, a novel nuclear tyrosine kinase expressed in epithelial cells. Cell Growth Differ. 1994; 5: 1347-1355.

63. Lee J, Wang Z, Luoh SM, Wood WI and Scadden DT. Cloning of FRK, a novel human intracellular SRC-like tyrosine kinase-encoding gene. Gene. 1994; 138: 247-251.

64. Craven RJ, Cance WG and Liu ET. The nuclear tyrosine kinase Rak associates with the retinoblastoma protein $\mathrm{pRb}$. Cancer Res. 1995; 55: 3969-3972.

65. Meyer T, Xu L, Chang J, Liu ET, Craven RJ and Cance WG. Breast cancer cell line proliferation blocked by the Src-related Rak tyrosine kinase. Int J Cancer. 2003; 104 : 139-146.

66. Yim EK, Peng G, Dai H, Hu R, Li K, Lu Y, Mills GB, Meric-Bernstam F, Hennessy BT, Craven RJ and Lin SY. Rak functions as a tumor suppressor by regulating PTEN protein stability and function. Cancer Cell. 2009; 15: 304314.

67. Jin L and Craven RJ. The Rak/Frk tyrosine kinase associates with and internalizes the epidermal growth factor receptor. Oncogene. 2014; 33: 326-335.

68. Li X, Lu Y, Liang K, Hsu JM, Albarracin C, Mills GB, Hung MC and Fan Z. Brk/PTK6 sustains activated EGFR signaling through inhibiting EGFR degradation and transactivating EGFR. Oncogene. 2012.

69. Kang SA and Lee ST. PTK6 promotes degradation of c-Cbl through PTK6-mediated phosphorylation. Biochem Biophys Res Commun. 2013; 431: 734-739.

70. Peng M, Ball-Kell SM, Franks RR, Xie H and Tyner AL. Protein tyrosine kinase 6 regulates mammary gland tumorigenesis in mouse models. Oncogenesis. 2013; 2: e81.

71. Regan Anderson TM, Peacock DL, Daniel AR, Hubbard GK, Lofgren KA, Girard BJ, Schorg A, Hoogewijs D, Wenger RH, Seagroves TN and Lange CA. Breast tumor kinase (Brk/PTK6) is a mediator of hypoxia-associated breast cancer progression. Cancer Res. 2013; 73: 58105820 .

72. Locatelli A, Lofgren KA, Daniel AR, Castro NE and Lange CA. Mechanisms of HGF/Met signaling to Brk and Sam68 in breast cancer progression. Horm Cancer. 2012; 3: 14-25.

73. Castro NE and Lange CA. Breast tumor kinase and 
extracellular signal-regulated kinase 5 mediate Met receptor signaling to cell migration in breast cancer cells. Breast Cancer Res :BCR. 2010; 12: R60.

74. Ai M, Qiu S, Lu Y and Fan Z. HER2 regulates Brk/PTK6 stability via upregulating calpastatin, an inhibitor of calpain. Cell Signal. 2013; 25: 1754-1761.

75. Ai M, Liang K, Lu Y, Qiu S and Fan Z. Brk/PTK6 cooperates with HER2 and Src in regulating breast cancer cell survival and epithelial-to-mesenchymal transition. Cancer Biol Ther. 2013; 14: 237-245.

76. Lu X and Li Y. Drosophila Src42A is a negative regulator of RTK signaling. Dev Biol. 1999; 208: 233-243.

77. Goel RK, Miah S, Black K, Kalra N, Dai C and Lukong KE. The unique $\mathrm{N}$-terminal region of SRMS regulates enzymatic activity and phosphorylation of its novel substrate docking protein 1. The FEBS journal. 2013; 280: 4539-4559.

78. Kohmura N, Yagi T, Tomooka Y, Oyanagi M, Kominami R, Takeda N, Chiba J, Ikawa Y and Aizawa S. A novel nonreceptor tyrosine kinase, Srm:cloning and targeted disruption. Mol Cell Biol. 1994; 14: 6915-6925.

79. Ji H, Li D, Chen L, Shimamura T, Kobayashi S, McNamara K, Mahmood U, Mitchell A, Sun Y, Al-Hashem R, Chirieac LR, Padera R, Bronson RT, Kim W, Janne PA, Shapiro GI, et al. The impact of human EGFR kinase domain mutations on lung tumorigenesis and in vivo sensitivity to EGFRtargeted therapies. Cancer Cell. 2006; 9: 485-495.

80. Lynch TJ, Bell DW, Sordella R, Gurubhagavatula S, Okimoto RA, Brannigan BW, Harris PL, Haserlat SM, Supko JG, Haluska FG, Louis DN, Christiani DC, Settleman $J$ and Haber DA. Activating mutations in the epidermal growth factor receptor underlying responsiveness of non-small-cell lung cancer to gefitinib. New England J Med. 2004; 350: 2129-2139.

81. Paez JG, Janne PA, Lee JC, Tracy S, Greulich H, Gabriel S, Herman P, Kaye FJ, Lindeman N, Boggon TJ, Naoki K, Sasaki H, Fujii Y, Eck MJ, Sellers WR, Johnson BE, et al. EGFR mutations in lung cancer:correlation with clinical response to gefitinib therapy. Science. 2004; 304(5676): 1497-1500.

82. Pao W, Miller V, Zakowski M, Doherty J, Politi K, Sarkaria I, Singh B, Heelan R, Rusch V, Fulton L, Mardis E, Kupfer D, Wilson R, Kris M and Varmus H. EGF receptor gene mutations are common in lung cancers from "never smokers" and are associated with sensitivity of tumors to gefitinib and erlotinib. Proc Natl Acad Sci U S A. 2004; 101: 13306-13311.
83. Sordella R, Bell DW, Haber DA and Settleman J. Gefitinibsensitizing EGFR mutations in lung cancer activate antiapoptotic pathways. Science. 2004; 305: 1163-1167.

84. Furukawa $M$, Nagatomo I, Kumagai $T$, Yamadori $T$, Takahashi R, Yoshimura M, Yoneda T, Takeda Y, Goya S, Matsuoka H, Kijima T, Yoshida M, Osaki T, Tachibana I, Greene MI and Kawase I. Gefitinib-sensitive EGFR lacking residues 746-750 exhibits hypophosphorylation at tyrosine residue 1045, hypoubiquitination, and impaired endocytosis. DNA and Cell Biol. 2007; 26: 178-185.

85. Chen YR, Fu YN, Lin CH, Yang ST, Hu SF, Chen YT, Tsai SF and Huang SF. Distinctive activation patterns in constitutively active and gefitinib-sensitive EGFR mutants. Oncogene. 2006; 25: 1205-1215.

86. Padron D, Sato M, Shay JW, Gazdar AF, Minna JD and Roth MG. Epidermal growth factor receptors with tyrosine kinase domain mutations exhibit reduced $\mathrm{Cbl}$ association, poor ubiquitylation, and down-regulation but are efficiently internalized. Cancer Res. 2007; 67: 7695-7702.

87. Liccardi G, Hartley JA and Hochhauser D. EGFR nuclear translocation modulates DNA repair following cisplatin and ionizing radiation treatment. Cancer Res. 2011; 71: 11031114.

88. Grandal MV, Zandi R, Pedersen MW, Willumsen BM, van Deurs B and Poulsen HS. EGFRvIII escapes downregulation due to impaired internalization and sorting to lysosomes. Carcinogenesis. 2007; 28: 1408-1417.

89. Naruo Y, Nagashima T, Ushikoshi-Nakayama R, Saeki Y, Nakakuki T, Naka T, Tanaka H, Tsai SF and OkadaHatakeyama M. Epidermal growth factor receptor mutation in combination with expression of MIG6 alters gefitinib sensitivity. BMC Systems Biol. 2011; 5: 29.

90. Walsh AM and Lazzara MJ. Regulation of EGFR trafficking and cell signaling by Sprouty2 and MIG6 in lung cancer cells. J Cell Sci. 2013; 126: 4339-4348.

91. Guha U, Chaerkady R, Marimuthu A, Patterson AS, Kashyap MK, Harsha HC, Sato M, Bader JS, Lash AE, Minna JD, Pandey A and Varmus HE. Comparisons of tyrosine phosphorylated proteins in cells expressing lung cancer-specific alleles of EGFR and KRAS. Proc Natl Acad Sci U S A. 2008; 105: 14112-14117.

92. Schmidt MH, Furnari FB, Cavenee WK and Bogler O. Epidermal growth factor receptor signaling intensity determines intracellular protein interactions, ubiquitination, and internalization. Proc Natl Acad Sci U S A. 2003; 100: 6505-6510. 